\title{
Sympathetic Nerve Injury in Thyroid Cancer
}

\author{
Evangelos Diamantis ${ }^{1}$, Paraskevi Farmaki ${ }^{1}$, Spyridon Savvanis², Georgios Athanasiadis ${ }^{3}$, \\ Theodoros Troupis ${ }^{1, *}$, Christos Damaskos ${ }^{4}$
}

\begin{abstract}
The double innervation of the thyroid comes from the sympathetic and parasympathetic nervous system. Injury rates during surgery are at $30 \%$ but can be minimized by upwardly preparing the thyroid vessels at the level of thyroid capsule. Several factors have been accused of increasing the risk of injury including age and tumor size. Our aim was to investigate of there is indeed any possible correlations between these factors and a possible increase in injury rates following thyroidectomy.

Seven studies were included in the meta-analysis. Statistical correlation was observed for a positive relationship between injury of the sympathetic nerve and thyroid malignancy surgery $\left(p<0.001 ; I^{2}=74 \%\right)$ No statistical correlations were observed for a negative or positive relationship between injury of the sympathetic nerve and tumor size. There was also no statistically significant value observed for the correlation of the patients' age with the risk of sympathetic nerve injury $(p=0.388)$. Lack of significant correlation reported could be due to the small number of studies and great heterogeneity between them.
\end{abstract}

\section{KEYWORDS}

thyroid neoplasm; sympathetic innervation; thyroidectomy

AUTHOR AFFILIATIONS

${ }^{1}$ Department of Anatomy, National and Kapodistrian University of Athens, Greece

2 Department of Internal Medicine General Hospital of Athens "Elpis", Athens, Greece

3 Thoracic Clinic, Red Cross Hospital, Athens, Greece

${ }^{4}$ Second Department of Propedeutic Surgery, Laiko General Hospital, Medical School, National and Kapodistrian University of Athens, Athens, Greece

* Corresponding author: Mikras Asias 75 Street, Athens, Greece; e-mail: ttroupis@gmail.com

Received: 26 June 2017

Accepted: 26 October 2017

Published online: 23 April 2018

Acta Medica (Hradec Králové) 2017; 60(4): 135-139

https://doi.org/10.14712/18059694.2018.8

(C) 2017 The Authors. This is an open-access article distributed under the terms of the Creative Commons Attribution License (http://creativecommons.org/licenses/by/4.0), which permits unrestricted use, distribution, and reproduction in any medium, provided the original author and source are credited. 


\section{INTRODUCTION}

Thyroid gland is considered as one of the most important glands of the human body (12). The complexity of the coordinated operations is reflected in its dual innervation which comes from the sympathetic and parasympathetic nervous system. Adrenergic postganglionic sympathetic fibers are vasomotor; they originate from the top and the middle cervical sympathetic ganglion and enter the gland along with its arteries. The preganglionic parasympathetic fibers originate from the vagus nerve and reach the gland with the branches of the laryngeal nerves. They also innervate the vasculature of the gland - regulating blood circulation - and indirectly affect the secretory function (20).

Knowing the topographical anatomy of the recurrent laryngeal nerve is crucial in the case of thyroid gland surgical removal, since a nerve injury may result in hoarseness or even mutism if there is a bilateral lesion. On the other hand, although not always identified due to anatomical variations, the external laryngeal nerves innervate the cricothyroid muscle (25). Taking into account its anatomical relationship to the superior thyroid artery, a possible injury during surgery could have severe complications in patients' quality life such as voice fatigue, decreased voice volume and range. Interestingly, the frequency of external branch of superior laryngeal nerve's palsy rages from $0.3 \%$ to $58 \%(21)$.

The thyroid carcinomas constitute about $0.6 \%$ of all malignant tumors in men and $1.6 \%$ in women, while in Europe, between 1978 and 1997, the appearance of thyroid carcinomas increased by about $3 \%$ (5). Prognosis and treatment depends on the type of thyroid cancer, tumor size and early diagnosis. Moreover, though patients' overall prognosis is considered excellent, it is widely accepted that thyroid carcinomas have a high risk of metastases occurrence, mainly through perineural filtration; cancerous cells could be installed on any tissue along the neural axis filter and then be transferred to the respective blood vessel $(7,3,12)$. Moreover, once the nerve fibers from metastatic cells of the thyroid's primary tumors are affected, this metastasis can be applied to the same nerve fibers, resulting in their overstimulation or understimulation $(6,13)$. These distant metastases are used as prognosis markers. However, until now, the issue of whether the sympathetic innervation is associated with the prognosis of primary malignant tumors has not been clarified. Total thyroidectomy is considered the treatment of choice in thyroid gland malignancies $(19,2)$. Though only rarely mentioned, there is a possibility of injury to each specific nerve, especially in larger tumors. In our study, we want to examine the relationship between the malignancies of the thyroid gland and the injury risk to the sympathetic nerve aggregated.

\section{MATERIALS AND METHODS}

\section{DATA COLLECTION}

Information on clinical trials conducted between 2007 and 2015 was searched on the databases Scopus, Medline (PubMed), Cochrane Library and Clinicaltrials.org. The terms used had only the search link * AND, (e.g., Thyroid carcinoma * AND sympathetic innervation), so the results comprised all studies reporting in both search terms' sets. The data collection included all studies related to the types of thyroid malignancies, including thyroid cancer, the existence of sympathetic nerve trauma or injury absence. We also performed a search on the references of the retrieved studies and on the table of contents of periodicals related to the thyroid and its malignancies and surgical journals that publish articles on thyroidectomy. Finally, we studied the references of other systematic studies or meta- analyses of the same topic to find any additional sources within the timeline during the past three years.

\section{STUDIES SELECTION}

The parameters on which the articles were selected are listed below:

a. Inclusion of both genders in the research;

b. Reference of the average ages in the studied groups;

c. Type of carcinoma;

d. Existence of metastases;

e. Number of nodes (metastatic and non);

f. Existence and number of outbreaks;

g. Existence and number of nodules;

h. Existence of thyroidectomy;

i. Existence of temporary or permanent injury or paralysis of sympathetic innervation of the thyroid.

We did not include single case studies or single case analyses, since it would not be possible to extract sufficient information on group comparison from such studies. Finally, studies in the form of abstracts from conferences and scientific meetings were not included in the analysis. We did not include studies with less than 100 participants.

After thorough research and categorization of studies, the final number of studies used for the meta-analysis and further statistical correlation was seven. For all of the parameters tested, we calculated the frequencies and their distributions. In response to the patients' age and tumor size, we calculated the averages, which were then used in subsequent analysis.

\section{STATISTICAL ANALYSIS}

OpenMetaAnalyst for Windows 7 64-bit software - complete and free software designed and distributed from Brown University Public Health - and IBM SPSS statistical package version 22 were used for the analysis, while the description model used was the fixed effects model. To confirm the accuracy of the results, three different computer models, whose results converge, were used. The model chosen for the description of the analysis is the fixed effects model (9). The statistical correlations examined are listed below:

- The relationship of patient's age to the likelihood of sympathetic nerve of thyroid injury;

- The correlation of the type of thyroid carcinoma with the probability of sympathetic nerve injury;

- The correlation of tumor size with the possibility of sympathetic nerve injury during thyroidectomy;

- The correlation of metastatic lymph nodes with the possibility of sympathetic nerve injury; 
- The relationship between the coexistence of thyroiditis in patients with thyroid cancer with sympathetic nerve injury.

The analyses were performed with $\chi^{2}$ methods for proving the existence of possible correlation parameters, followed by ANOVA analysis, to detect any statistical difference between the types of parameters used. All parameters studied and analyzed were grouped into categories according to their means and distribution.

To assess the investigation sensitivity, the overall reasons mutandis (summary odds ratios (ORs)) were calculated, as well as their confidence intervals. The confidence interval was chosen in accordance with the limits set out in all normal Gauss distributions and, therefore, in our study, confidence intervals are at $95 \%$. The heterogeneity between studies is estimated as a measure of heterogeneity and is denoted as $I^{2}$, which is a parameter calculated from a prior statistic called the $\mathrm{Q}$ statistic $\left\{\mathrm{I}^{2}=[(\mathrm{Q}-\mathrm{df}) / \mathrm{Q}] \times\right.$ $100\}$. This relationship describes the variability rate of the sample, which is due to the heterogeneity of the sample due to different sizes in the studies involved in the analysis rather than an error of the sampling. While the variable $Q$ statistic depends on the number of the studies involved in the analysis, the $\mathrm{I}^{2}$ values are between $0-100 \%$. In a broad- er research context, values totaling more than $50 \%$ are considered to express great heterogeneity $(6,16)$.

\section{RESULTS}

The trials included in our meta-analysis study the permanent injury of the sympathetic nerve after surgery, the temporary injury of the sympathetic nerve, the presence of other side effects after surgery and the complete absence of injury and side effects. The seven studies fulfilling the requirements are shown in tables (Table 1).

The mean patients' age per study was 46.6131 years and the average tumor size was $1.69 \mathrm{~cm}$. The average number of male patients is 46.69 men per survey, while the average number of female patients is 212.54 per survey 4.55 times more than men. There were 123 breakouts on average in patients per study and 201.33 metastatic lymph nodes, contributing to the aggressiveness of the disease. The types of thyroid malignancies observed in this study were papillary carcinoma, follicular carcinoma and goiter, and there was one study that reported Graves's disease.

The sensitivity of our sample ranges from 0.382 to 0.472 . Though the sensitivity of each survey sample does

Tab. 1 Studies included in the meta-analysis. M: men, W: women.

\begin{tabular}{|c|c|c|c|c|c|c|c|c|c|}
\hline Study & $\begin{array}{l}\text { Neoplasm } \\
\text { type }\end{array}$ & $\begin{array}{l}\text { Patients' } \\
\text { age }\end{array}$ & $\begin{array}{l}\text { Patients } \\
\text { (N) }\end{array}$ & $\begin{array}{l}\text { Tumor } \\
\text { size }\end{array}$ & $\begin{array}{l}\text { Breakouts } \\
\text { (N) }\end{array}$ & $\begin{array}{l}\text { Lymph } \\
\text { nodes (N) }\end{array}$ & Thyroidotis & $\begin{array}{l}\text { Metastases } \\
\text { (N) }\end{array}$ & $\begin{array}{l}\text { State of } \\
\text { sympathetic } \\
\text { innervation }\end{array}$ \\
\hline Chang 2016 [6] & $\begin{array}{l}\text { papillary } \\
\text { thyroid } \\
\text { carcinoma }\end{array}$ & 46.2 & $\begin{array}{l}613 \text { (M: 55, } \\
W: 558)\end{array}$ & 0.8 & 152 & 239 & 293 & 1 & Injury \\
\hline Kwon 2015 [16] & $\begin{array}{l}\text { papillary } \\
\text { thyroid } \\
\text { carcinoma }\end{array}$ & 53.3 & $\begin{array}{l}10(M: 1 \\
W: 9)\end{array}$ & 0.96 & - & 19 & - & 1 & No injury \\
\hline Gao 2015 [10] & $\begin{array}{l}\text { papillary } \\
\text { thyroid } \\
\text { carcinoma }\end{array}$ & 32.02 & $\begin{array}{l}137(M: 2, \\
W: 135)\end{array}$ & 0.82 & - & - & - & - & Injury \\
\hline Kihara 2014 [15] & $\begin{array}{l}\text { papillary } \\
\text { thyroid } \\
\text { carcinoma }\end{array}$ & 59.9 & $\begin{array}{l}18(M: 3 \\
W: 15)\end{array}$ & - & - & - & 391 & - & Injury \\
\hline Lang 2014 [17] & $\begin{array}{l}\text { papillary } \\
\text { thyroid } \\
\text { carcinoma }\end{array}$ & 46.1 & $\begin{array}{l}1291 \\
(M: 188, \\
W: 1103)\end{array}$ & 0.8 & 425 & 845 & $\begin{array}{l}\text { Graves' } \\
\text { disease }\end{array}$ & 845 & No injury \\
\hline $\begin{array}{l}\text { Giannopoulos } \\
2013[11]\end{array}$ & $\begin{array}{l}\text { follicular } \\
\text { carcinoma }\end{array}$ & 38.2 & $\begin{array}{l}44(M: 5 \\
W: 139)\end{array}$ & 1.68 & - & - & - & - & Injury \\
\hline Wang 2014 [24] & $\begin{array}{l}\text { papillary } \\
\text { thyroid } \\
\text { carcinoma }\end{array}$ & 50 & $\begin{array}{l}188 \text { (M: } 35 \\
W: 153)\end{array}$ & 1.2 & 144 & 83 & - & - & \\
\hline Lee 2015 [18] & $\begin{array}{l}\text { papillary } \\
\text { thyroid } \\
\text { carcinoma }\end{array}$ & 49 & $\begin{array}{l}34(M: 10, \\
W: 24)\end{array}$ & 2 & 17 & 22 & - & 43 & Injury \\
\hline Tamatea 2014 [23] & $\begin{array}{l}\text { papillary } \\
\text { thyroid } \\
\text { carcinoma }\end{array}$ & 42 & $\begin{array}{l}8(M: 2, \\
W: 6)\end{array}$ & 0.57 & - & - & 218 & - & No injury \\
\hline Conzo 2014 [8] & $\begin{array}{l}\text { follicular } \\
\text { carcinoma }\end{array}$ & 46.65 & $\begin{array}{l}712(\mathrm{M}: 197, \\
\text { W: } 524)\end{array}$ & 1.76 & - & - & - & - & No injury \\
\hline Boute 2013 [4] & $\begin{array}{l}\text { follicular } \\
\text { carcinoma }\end{array}$ & 51 & $\begin{array}{l}83(M: 37, \\
W: 46)\end{array}$ & 1 & - & - & - & - & Injury \\
\hline Perie 2013 [22] & $\begin{array}{l}\text { Graves' } \\
\text { disease, } \\
\text { goiter }\end{array}$ & 47.1 & $\begin{array}{l}100 \text { (M: } 19, \\
\text { W: } 81)\end{array}$ & - & - & - & $\begin{array}{l}\text { 1, Graves' } \\
\text { disease (27) }\end{array}$ & - & Injury \\
\hline
\end{tabular}


Tab. 2 Sensitivity results and confidence intervals for the studies of the meta-analysis.

\begin{tabular}{|l|l|l|l|l|l|l|}
\hline Study & $\begin{array}{l}\text { Sample } \\
\text { sensitivity }\end{array}$ & $\begin{array}{l}\text { Upper limit } \\
\mathbf{( 9 5 \% )}\end{array}$ & $\begin{array}{l}\text { Lower limit } \\
\mathbf{( 9 5 \% )}\end{array}$ & Sample specialty & $\begin{array}{l}\text { Upper limit } \\
\mathbf{( 9 5 \% )}\end{array}$ & $\begin{array}{l}\text { Lower limit } \\
\mathbf{( 9 5 \% )}\end{array}$ \\
\hline Boute 2013 [4] & 0.098 & 0.037 & 0.233 & 0.786 & 0.637 & 0.885 \\
\hline Chang 2016 [6] & 0.026 & 0.006 & 0.097 & 0.976 & 0.959 & 0.986 \\
\hline Gao 2015 [10] & 0.143 & 0.020 & 0.581 & 0.974 & 0.923 & 0.992 \\
\hline Kihara 2014 [15] & 0.875 & 0.266 & 0.993 & 0.156 & 0.046 & 0.417 \\
\hline Perie 2013 [22] & 0.900 & 0.326 & 0.994 & 0.809 & 0.719 & 0.876 \\
\hline Tamatea 2014 [23] & 0.075 & 0.015 & 0.300 & 0.995 & 0.924 & 1.000 \\
\hline Wang 2014 [24] & 0.045 & 0.003 & 0.448 & 0.992 & 0.960 & 0.998 \\
\hline
\end{tabular}

not seem to be great, it would not affect the analysis due to the small number of patients participating in the study. The sample specialty ranges from 0.860 to 0.869 , with the majority of values above 0.65 . The values of the sample specialty range at the same level, ensuring a common logic in the investigations, despite the different circumstances considered and the direction followed (Table 2).

In the independent variables model we used, if considered a negative correlation with the injury of the sympathetic nerve, we do not have a significant value to indicate the thyroidectomy in patients with thyroid malignancies is negatively associated with sympathetic nerve injury. This result is supported by calculations for the heterogeneity of individual research of meta-analysis. The value of $\mathrm{Q}=22.950$ indicates medium heterogeneity of individual investigations and that value is verified by the statistical variable $I^{2}$, where the significance value of the variable $Q$ is less than 0.001 , and the value $\mathrm{I}^{2}=74 \%$ indicates medium heterogeneity of individual studies. Such heterogeneity observed is due to the nature of the meta-analysis and the research limits we have set, allowing a small number of studies to be included in this study. Therefore, we found a positive correlation between malignancy of thyroid cancer and injury of the sympathetic nerve tends to be statistically significant.

Subsequently, the analysis for odds ratio factor was done. The value $<0.001$ is similar to that of the positive correlation of thyroid malignancy presence and sympathetic nerve injury during thyroidectomy.

Then, we performed statistical analyses of the individual studies to find the existence of a particular association. Initially, the descriptive statistics values of the parameter used in the statistical analysis were calculated. The parameters that provided sufficient and adequate information to be readily available and give good quality results are: the type of malignancy, the age, the numbers of male and female patients, the size of the tumor in $\mathrm{cm}$, the number of outbreaks and the number of nodes.

The other parameters - shown in Table 1 - not included in the statistical analysis did not provide enough information or had deficiencies per survey, or they did not show homogeneity and, therefore, we did not prefer them for our analysis.

We also wanted to examine the possible relationship between the tumor size and sympathetic nerve injury. Patients were divided into two groups: tumors having a volume of less than $1.7 \mathrm{~cm}$ and those greater than $1.7 \mathrm{~cm}$. The significance value of this statistic was 0.618 indicating no correlation between the tumor size and the sympathetic nerve injury during thyroidectomy. In addition, we wanted to examine the existence of correlation between the age of patients and sympathetic nerve injury. Patients were grouped into two categories: those older than 46 years and patients aged less than 46 years. The statistical likelihood ratio was used, reaching a statistical significance value of 0.388 , which is much greater than the significance threshold of 0.05 .

Finally, we wanted to test whether there is a correlation between the type of thyroid malignancy and sympathetic nerve injury. The malignancy groups are those mentioned above (i.e., one group is that of patients suffering from papillary carcinoma, one of patients suffering from follicular carcinoma and one of patients with goiter). The significance value for this parameter was 0.877 , which shows that the type of thyroid malignancy is not related to sympathetic nerve injury in patients (likelihood ratio).

\section{DISCUSSION}

The prognosis of primary malignant neoplasms of the thyroid gland is high, and it sometimes reaches $90 \%$ for a five-year survival (22). Though many factors have been proposed - such as patient's age, tumor differentiation grade, extrathyroidal extension in the surrounding tissue, the presence of distant metastatic foci, the size of the primary tumor and others - as indicators of survival, their prognostic value is debatable (1). Sympathetic innervation is directly involved with thyroid gland neoplasms, and often during a surgical intervention, its proper functioning could be affected either transiently or permanently, thus leading to complete loss of the gland functions. Taking all these into account, we conducted a meta-analysis of relevant studies during the past 3 years to investigate if there is a negative or positive correlation between the development of all types of thyroid neoplasms and sympathetic nerve injury risk.

Chang et al. examined the risk factors and incidence of central lymph node metastases (CLNMs) in 631 patients with papillary thyroid microcarcinoma (PTMC) who underwent thyroidectomy and central lymph node dissection (CLNM). Researchers conclude that male sex, tumor size $\geq 0.5 \mathrm{~cm}$, extrathyroidal extension and multifocality are independent risk factors for CLNM in PTMC (6). Moreover, Kwon et al. proved the ultrasound-guided charcoal 
tattooing localization is safe and feasible in patients with papillary thyroid carcinoma (16). The bilateral areolar approach endoscopic thyroidectomy has also been evaluated as an alternate therapeutic treatment in selected patients with low-risk papillary thyroid carcinoma (PTC). Though this approach was found feasible and safe, large comparative series and long-term follow-up studies are needed to verify its oncologic safety (10).

Another important consideration is the possible thickening of the recurrent laryngeal nerve after thyroidectomy. Kihara et al. showed no impairment in the vocal cords' function in the vast majority of patients with papillary thyroid cancer (15). Boute et al. mentioned that despite central compartment dissection being associated with total thyroidectomy, it does not increase the risk of recurrent laryngeal nerve paralysis or permanent hypoparathyroidism and was found to be responsible for increased rates of transient hypoparathyroidism in differentiated thyroid carcinoma of the follicular epithelium (4).

Any systematic review and meta-analysis has a potential weakness of missing unpublished trials and a potential individual trial heterogeneity difficult to account for in analysis. It is obvious from the published trials that before-and-after trials tend to overestimate effectiveness, and even variation in the length of a randomized trial may affect the ability to detect underlying benefits.

In conclusion, the corresponding correlation models examined showed no significant associations for the parameters studied probably due to the small number of available studies and great heterogeneity between the surveys. A research with broader limits can ensure a greater number of studies and a smoother distribution, leading to future clinical implications. In this way, more data would be available in the meta-analysis model, allowing accurate estimation of statistical variables and producing more reliable results, which can be used as a prediction database for risk of sympathetic nerve injury of patients with thyroid neoplasms.

\section{ACKNOWLEDGEMENTS}

All authors have contributed equally to the design and integration of this manuscript.

We have not received any funding for this study.

\section{REFERENCES}

1. Ariga $M$, Nedachi T, Akahori $M$, et al. Signalling pathways of insulin-like growth factor-I that are augmented by cAMP in FRTL- 5 cells. Biochem J 2000; 348: 409-416.

2. Asimakopoulos P, Nixon IJ. Surgical management of primary thyroid tumours. Eur J Surg Oncol 2018; 44(3):321-326.

3. Bodner L, Sion-Vardy N, Geffen DB, et al. Metastatic tumors to the jaws: a report of eight new cases. Med Oral Patol Oral Cir Bucal 2006; 11: 132-135.
4. Boute P, Merlin J, Biet A, et al. Morbidity of central compartment dissection for differentiated thyroid carcinoma of the follicular epithelium. Eur Ann Otorhinolaryngol Head Neck Dis 2013; 130(5): 245-249.

5. Bramley MD, Harrison BJ. Papillary microcarcinoma of the thyroid gland. BrJ Surg 1996; 83(12): 1674-1683.

6. Chang YW, Kim HS, Kim HY, et al. Should central lymph node dissection be considered for all papillary thyroid microcarcinoma? Asian J Surg 2016; 39(4): 197-201.

7. Chawla M, Kumar R, Malhotra A. Dual ectopic thyroid: case series and review of the literature. Clin Nucl Med 2007; 32(1): 1-5.

8. Conzo G, Calò PG, Gambardella C, et al. Controversies in the surgical management of thyroid follicular neoplasms. Retrospective analysis of 721 patients. Int J Surg 2014; 12 (Suppl 1): S29-34.

9. DerSimonian R, Laird N. Meta-analysis in clinical trials. Controlled Clinical Trials 1986; 7(3): 177-188.

10. Gao W, Liu L, Ye G, et al. Bilateral areolar approach endoscopic thyroidectomy for low-risk papillary thyroid carcinoma: a review of 137 cases (corrected). Surg Laparosc Endosc Percutan Tech 2015; 25(1): 19-22.

11. Giannopoulos G, Kang SW, Jeong JJ, et al. Robotic Thyroidectomy for Benign Thyroid Diseases: A Stepwise Strategy to the Adoption of Robotic Thyroidectomy (Gasless, Transaxillary Approach). Surg Laparosc Endosc Percutan Tech 2013; 23(3): 312-315.

12. Hirshberg A, Shnaiderman-Shapiro A, Kaplan I, et al. Metastatic tumours to the oral cavity. Pathogenesis and analysis of 673 cases. Oral Oncol 2008; 44(8): 743-752.

13. Ismail S, Abraham M, Zaini Z, et al. Metastatic follicular thyroid carcinoma to the mandible: a case report. Cases J 2009; 29(2): 6533 .

14. Jameson JL, De Groot LJ (eds). Endocrinology: The Thyroid Gland. 6th Edition. Elsevier Health Sciences, USA, 2013.

15. Kihara M, Miyauchi A, Yabuta T, et al. Outcome of vocal cord function after partial layer resection of the recurrent laryngeal nerve in patients with invasive papillary thyroid cancer. Surgery 2014; 155(1): 184-189.

16. Kwon H, Tae SY, Kim SJ, et al. Role of charcoal tattooing in localization of recurred papillary thyroid carcinoma: initial experiences. Ann Surg Treat Res 2015; 88(3): 140-144.

17. Lang BH, Chai YJ, Cowling BJ, et al. Is BRAFV600E mutation a marker for central nodal metastasis in small papillary thyroid carcinoma? Endocr Relat Cancer 2014; 21(2): 285-295.

18. Lee HS, Kim SW, Park T, et al. Papillary Thyroid Carcinoma with Exclusive Involvement of a Functioning Recurrent Laryngeal Nerve May Be Treated with Shaving Technique. World J Surg 2015; 39(4): 969-974.

19. Lu WT, Sun SQ, Huang J, et al. An applied anatomical study on the external laryngeal nerve loop and the superior thyroid artery in the neck surgical region. Anat Sci Int 2015; 90(4): 209-215.

20. Melmed S, Polonsky KS, Larsen PR, Kronenberg HM. Williams Textbook of Endocrinology. 13th edition. Elsevier, USA, 2016.

21. Ozlugedik S, Acar HI, Apaydin N, et al. Surgical Anatomy of the External Branch of the Superior Laryngeal Nerve. Clinical Anatomy 2007; 20: 387-391.

22. Passler C, Scheuba C, Prager G, et al. Prognostic factors of papillary and follicular thyroid cancer: difference in an iodine-replete endemic goiter region. Endocr Related Cancer 2004; 11(1): 131-139.

23. Périé S, Ait-Mansour A, Devos M, et al. Value of recurrent laryngeal nerve monitoring in the operative strategy during total thyroidectomy and parathyroidectomy. Eur Ann Otorhinolaryngol Head Neck Dis 2013; 130(3): 131-136.

24. Tamatea JA, Tu'akoi K, Conaglen JV, et al. Thyroid cancer in Graves' disease: is surgery the best treatment for Graves' disease? ANZ J Surg 2014; 84(4): 231-234.

25. Taytawat P, Viravud Y, Plakornkul V, et al. Identification of the external laryngeal nerve: its anatomical relations to inferior constrictor muscle, superior thyroid artery, and superior pole of the thyroid gland in Thais. J Med Assoc Thai 2010; 93(8): 961-968.

26. Wang $Q, C h u B, Z$ hu J, et al. Clinical analysis of prophylactic central neck dissection for papillary thyroid carcinoma. Clin Transl Oncol 2014; 16(1): 44-48. 